\title{
Precipitation and Damaging Floods: Trends in the United States, 1932-97
}

\author{
Roger A. Pielke JR. And Mary W. Downton \\ Environmental and Societal Impacts Group, National Center for Atmospheric Research, ${ }^{*}$ Boulder, Colorado
}

(Manuscript received 16 March 1999, in final form 6 January 2000)

\section{ABSTRACT}

\begin{abstract}
The poor relationship between what climatologists, hydrologists, and other physical scientists call floods, and those floods that actually cause damage to life or property, has limited what can be reliably said about the causes of observed trends in damaging floods. It further limits what can be said about future impacts of floods on society based on predicted changes in the global hydrological cycle. This paper presents a conceptual framework for the systematic assessment of the factors that condition observed trends in flood damage. Using the framework, it assesses the role that variability in precipitation has in damaging flooding in the United States at national and regional levels. Three different measures of flood damage—absolute, per capita, and per unit wealth—each lead to different conclusions about the nature of the flood problem. At a national level, of the 10 precipitation measures examined in this study, the ones most closely related to flood damage are the number of 2-day heavy rainfall events and the number of wet days. Heavy rainfall events are defined relative to a measure of average rainfall in each area, not as absolute thresholds. The study indicates that the growth in recent decades in total damage is related to both climate factors and societal factors: increased damage is associated with increased precipitation and with increasing population and wealth. At the regional level, this study reports a stronger relationship between precipitation measures and flood damage, and indicates that different measures of precipitation are most closely related to damage in different regions. This study suggests that climate plays an important, but by no means determining, role in the growth in damaging floods in the United States in recent decades.
\end{abstract}

\section{Introduction}

Floods affect societies around the world. The Red Cross estimates that over the 25 -yr period ending in 1995 floods affected more than 1.5 billion people. Of that total, more than 318000 people were killed and more than 81 million people became homeless. In addition, during 1991-95 flood-related damage totaled more than $\$ 200 \times 10^{9}$ (not inflation adjusted) globally, representing close to $40 \%$ of all economic damage attributed to natural disasters in the period (IFRCRCS 1997). In October-November 1998, flooding related to Hurricane Mitch killed 9000 to 18000 in Central America. ${ }^{1}$ In the United States, flood-related loss of life has totaled about 100 annually (1983-97), while annual flood losses (inflation-adjusted) have increased from

\footnotetext{
${ }^{1}$ Source: K. Sponberg/NOAA Office of Global Programs, compiled from various sources.
}

* The National Center for Atmospheric Research is sponsored by the National Science Foundation.

Corresponding author address: Dr. Roger A. Pielke Jr., Environmental and Societal Impacts Group, NCAR, 3450 Mitchell Lane, Boulder, CO 80301.

E-mail: rogerp@ucar.edu about $\$ 1 \times 10^{9}$ in the 1940 s to about $\$ 5 \times 10^{9}$ in the 1990s (Fig. 1). ${ }^{2}$ This paper focuses specifically on economic damage related to floods.

In spite of the large impacts, discussion about floods by scientists and policy makers alike is characterized by confusion and imprecision (cf. Baker 1998; Changnon 1980). For instance, when climatologists discuss floods, they typically are referring to hydrologic floods, but when policy makers discuss floods they typically are referring to damaging floods (Pielke 1999). This situation is problematic as hydrologic floods are not necessarily associated with flood damage (Changnon 1998; Pielke 2000). The poor relationship between what climatologists, hydrologists, and other physical scientists call floods and those floods that actually cause damage has limited what can be reliably said about the causes of observed trends in flood damage. It further limits what can be reliably said about future impacts of floods on society based on predicted changes in the global hydrological cycle. As a step toward forging closer ties between research on hydrologic floods and decision makers' need to understand the causes of flood damage,

\footnotetext{
${ }^{2}$ Floods also have significant effects, both positive and negative, on ecosystems. This paper focuses on economic damage, recognizing that flood impacts are broader than are represented by any one metric.
} 
U.S. Flood Damage, 1932-1997

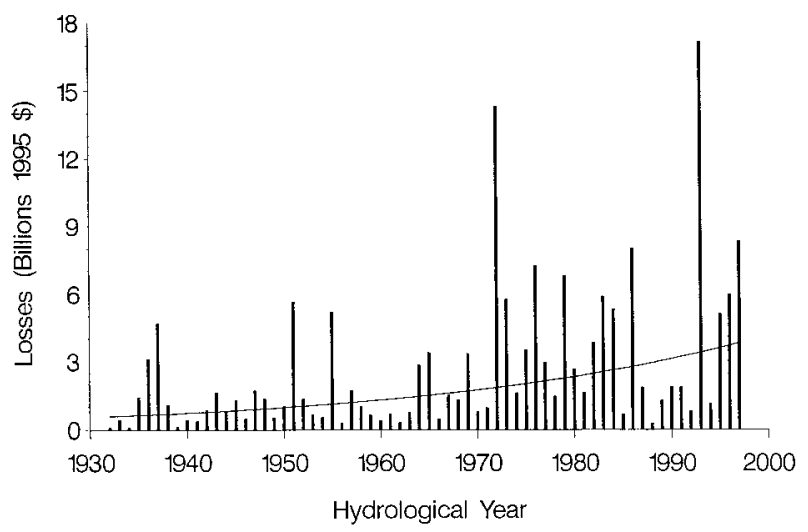

FIG. 1. U.S. flood damage 1932-97 adjusted to current 1995 dollars. The displayed trend is a transformation of a linear trend computed on the logarithm of losses.

this paper utilizes a definition of a damaging flood as a flood that results in damage to human life or property.

This paper has two objectives. First, it presents a conceptual framework for the systematic assessment of the factors that condition observed trends in damaging floods. Second, using the framework, it assesses the role that variability in precipitation has in damaging flooding in the case of the United States at national and regional levels. A broader objective of the research is to forge closer ties between physical and social sciences in order to improve understanding of the interface of climate and society. While recent research has focused on developing a better quantitative understanding of the societal impacts of extreme weather in the context of hurricanes and other phenomena (e.g., Kunkel et al. 1999; Pielke and Landsea 1998), an understanding of damaging floods remains elusive.

\section{Conceptual framework}

This paper builds upon a long history of research into the causes of damaging floods, and specifically the work of White (e.g., White et al. 1958) and Changnon (e.g., Changnon 1980). A damaging flood is the joint product of societal and climatological factors (as well as ecological, geological, etc.). The multiple factors that lead to damaging floods have led to a number of different explanations for the increasing trend in losses. For instance, some have speculated that the trend is indicative of a change in climate (e.g., Hamburger 1997); some blame population growth and development (e.g., Kerwin and Verrengia 1997); others place the blame on federal policies (e.g., Coyle 1993), and still others suggest that the trend actually distracts from the larger success of the nation's flood policies (e.g., Labaton 1993). Empirical evidence from a range of cases clearly shows that climate, population growth and development, and policy each play a role in trends in flood damage in the United States (e.g.,
Changnon 1996; FIFMTF 1992), but the state of knowledge is such that the relative contribution of each factor is poorly understood. The U.S. case seems typical of the more general circumstance: policy makers face difficulties in assessing the magnitude and causes of the flood problems that they face and in evaluating the effectiveness of past responses (Pielke 2000).

A small but significant literature relates quantitatively climatological aspects of floods with flood losses (Changnon and Demissie 1996; Moser 1994; Smith 1993; Changnon 1980; White et al. 1958; Renshaw 1957; Hoyt and Langbein 1955). Building on this literature, Fig. 2 shows a conceptual framework for understanding the multiple interactions of human and human-influenced processes related to damaging floods. ${ }^{3}$ An integrative framework has broad relevance to understanding the role of development, population growth, and policy in shaping actual and potential outcomes. This paper uses the framework to begin to address the relationship of trends in precipitation and trends in damaging floods in the case of the United States. An understanding of this relationship will inform discussion of national flood policies as well as broader discussions of natural hazards and climate change policy.

\section{Precipitation and flood damage}

As societal impacts related to climate have grown, climate variability has become of increasing concern to decision makers. In addition, a number of scientists have predicted that one of the consequences of anthropogenic emissions of greenhouse gases to the atmosphere will be an enhanced hydrologic cycle. In the words of the Intergovernmental Panel on Climate Change (IPCC): "there is now mounting evidence to suggest that a warmer climate will be one in which the hydrological cycle will in general be more intense, leading to more heavy rain events" (IPCC 1996a, p. 335). More recent theoretical and modeling research has supported the hypothesis (e.g., Trenberth 1998), and observational studies have provided additional support (e.g., Karl and Knight 1998; Karl et al. 1995a).

Based on such studies, scientists, journalists, and policy makers have variously suggested that an enhanced hydrologic cycle is responsible for the increasing flood damage of recent years. For instance, Karl and Knight (1998) introduce their research article on precipitation trends with a discussion of catastrophic flooding in the U.S. Midwest and in 1993 other floods. Trenberth (1997) conflates an observed 10\% increase in precipitation in the United States with the 1997 North Dakota floods, which crested 10\% higher than was predicted. In a 1997

\footnotetext{
${ }^{3}$ The framework is informed by multiple sources, the most important of which are White et al. (1958), Chandler et al. (1976), Changnon (1980), Ward and Robinson (1990), FIFMTF (1992), and Pielke (1996).
} 


\section{Factors Contributing to Damaging Floods}

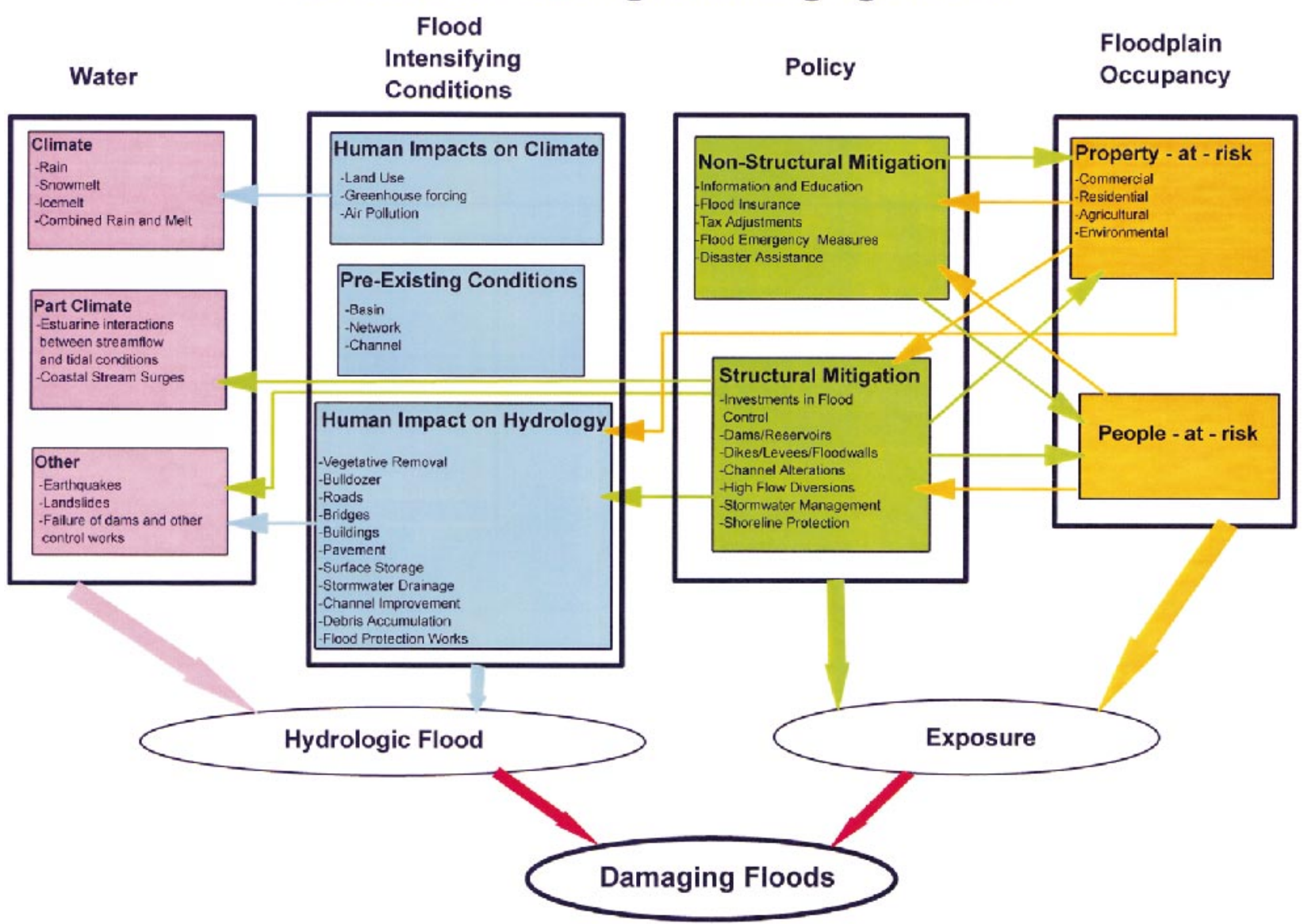

FIG. 2. Framework for understanding the interrelated factors responsible for the occurrence of damaging flood.

press release, the National Oceanic and Atmospheric Administration (NOAA) warned that "as the global climate continues to warm, extreme flooding like that recently experienced in the [Pacific Northwest] United States is expected to become more frequent" (NOAA 1997). ${ }^{4}$ Such statements have led many in the media to conclusions such as the following presented in the New York Times in 1997: "heavy rainstorms have become more common, making damaging floods more likely" (Stevens 1997). In turn, this has led decision makers to accept as conventional wisdom that climate factors underlie the growth in flood damage in the United States. For instance, James Lee Witt, director of the Federal Emergency Management Agency (FEMA), stated in November 1998 that "regardless of whether you believe the cause is global warming or natural changes in weather patterns, there is no disagreement that the frequency and severity of what we call 'weather events' are on

${ }^{4}$ The 1997 Pacific Northwest floods resulted in more than $\$ 1$ billion in damages. For an overview, see http://nic.fb4.noaa.gov/products/ special_summaries/97_1. the rise" (Witt 1998). Witt's views are important because approximately two-thirds of federally declared disasters, which FEMA reponds to, are related to floods (R. Sylves, personal communication).

Intuitively, it does seem that more precipitation would mean more flood damage. But some have questioned the validity of conventional wisdom. For instance, in a response to Karl and Knight (1998), Changnon (1998, p. 2551) argues that "there is considerable difference" between the type of precipitation climatologists label as extreme, and those rare events that cause tremendous societal damage. In a study of stream flow records, Lins and Slack (1999) find few trends in large-scale flooding. The IPCC (1996b, p. 202) has concluded that "little information is currently available regarding the socioeconomic impact of changes in the frequency and intensity of river floods" and thus does not include flood damage in its projections of the impacts of climate change. These various findings beg an important question with policy implications: If the hydrological cycle does become more vigorous, and precipitation does increase as predicted by climatologists, what changes in flood impacts might be expected? 
This study statistically models the relationship between flood damage and precipitation and identifies precipitation measures most closely related to historical flood damage. The conceptual framework (Fig. 2) suggests many factors that could be important in explaining historical and future damage trends. Hydrologic floods (the left-hand side of the framework) are generally measured using stream flow data and are related to precipitation. Exposure (the righthand side) might be equally important, although harder to measure. Exposure to flood damage depends on flood plain occupancy and on flood policies (Pielke 1999). Unfortunately, there are no direct measures of trends in flood plain occupancy and few evaluations of flood policies (Wiener 1996; FIFMTF 1992).

In the absence of such direct measures, this paper uses population and wealth as surrogate measures of exposure. Three different perspectives on flood damage are provided by considering three measures: total damage, damage per capita, and damage per unit of tangible wealth. The population and wealth data are used assuming that overall national trends in population growth and wealth represent trends in population and wealth in flood-prone regions.

Note that flood damage need not necessarily increase as population and wealth increase. If structural and nonstructural flood policies have reduced exposure, then flood damage per capita and per unit wealth might be expected to decline (even if total damage continues to increase; cf. Holliday et al. 1998).

\section{Data and methods}

The National Weather Service (NWS) maintains a national flood damage record for the period 1903 to present, and state level data 1983 to present. The reported losses are for "significant flood events" and include only direct economic damage that results from flooding due to rainfall and/or snowmelt. (Flooding due to winds, such as coastal flooding from hurricane storm surges, is not included.) The annual losses are based on "hydrological years," October-September. ${ }^{5}$ Researchers have significant concerns about the comprehensiveness of the data. But FEMA, the NWS, and the Federal Interagency Floodplain Management Task Force (FIFMTF) have each concluded that the data is of sufficient quality to be used for trend analysis (FEMA 1997; FIFMTF 1992; cf. Yen and Yen 1996; Pielke 2000). ${ }^{6}$

\footnotetext{
${ }^{5}$ Annual loss estimates from significant flooding events between 1903 and 1997 were obtained from the NWS Web site at http:// www.nws.noaa.gov/oh/hic/flood_stats/Flood_loss_time_series.htm. The data represent the "best estimate of direct damage due to flooding that results from rainfall and/or snowmelt." The data include government and private costs and are collected by the NWS Field Offices.

${ }^{6}$ The FIFMTF concluded that the NWS database is the "most complete and consistent information over the longest period of record" (FIFMTF 1992, 3-16). The NWS, on the WWW site referenced in footnote 3 , has concluded that "while the damage amounts for individual years are not precise, they provide reasonable indications of relative changes over time."
}

(a) U.S. Per Capita Flood Damage, 1932-1997

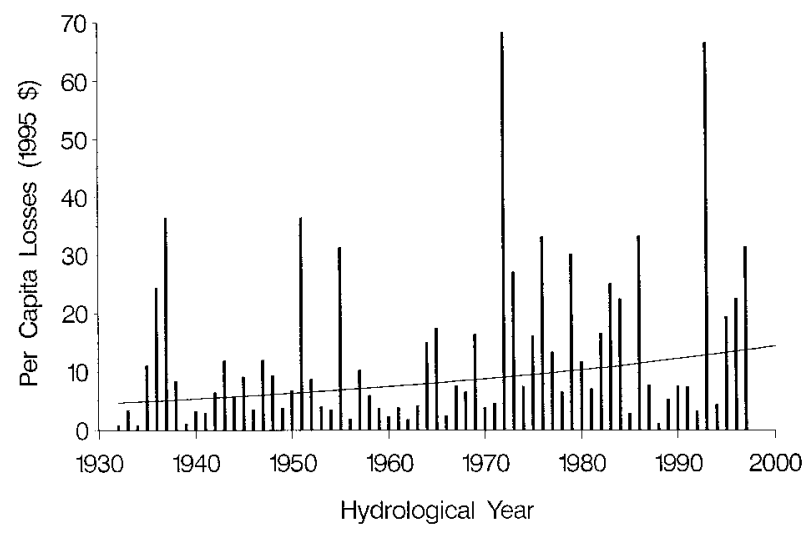

(b) U.S. Flood Damage per Unit Wealth, 1932-1997

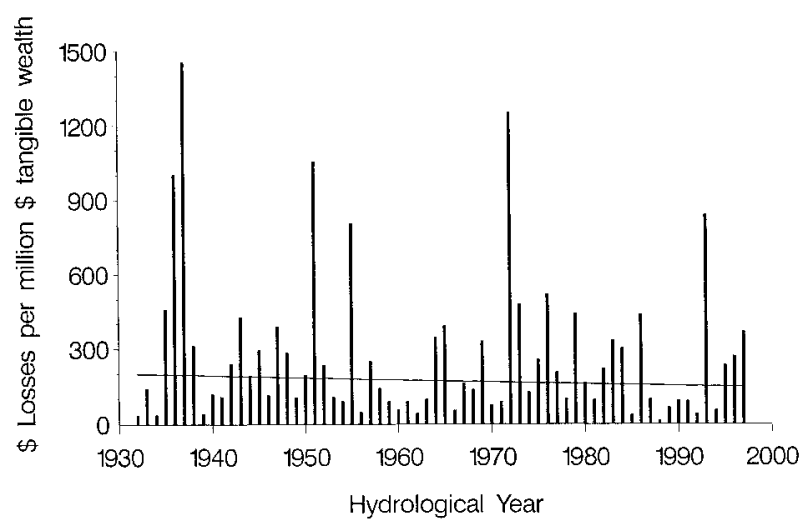

FIG. 3. (a) U.S. per capita flood damage 1932-97 adjusted to current 1995 dollars. (b) U.S. flood losses per million dollars tangible wealth 1932-97 adjusted to current 1995 dollars.

Flood damage per capita (1932-97, Fig. 3a) is computed by dividing the inflation-adjusted losses for each hydrological year by the estimated population on 1 July of that year (www.census.gov). Flood damage per million dollars of national wealth (1932-97, Fig. 3b) uses the net stock of fixed reproducible tangible wealth as estimated by the U.S. Department of Commerce, Bureau of Economic Analysis (www.bea.doc.gov), for 31 December of each year, in current dollars (depreciating stock carried over from prior years). Unadjusted flood damage is divided by the tangible wealth in millions of current dollars. Thus, the flood damage per million dollars of tangible wealth reflects the proportion of the nation's wealth in that year lost due to floods.

Annual flood loss estimates for each state are readily available only since 1983, when the U.S. Army Corps of Engineers began publishing an annual flood damage report for Congress. ${ }^{7}$ In conducting a regional analysis,

\footnotetext{
${ }^{7}$ However, the FIFMTF (1992, 3-16) notes that state level data was collected prior to 1976. According to F. Richards (1997, personal
} 


\section{U.S. Climate Regions}

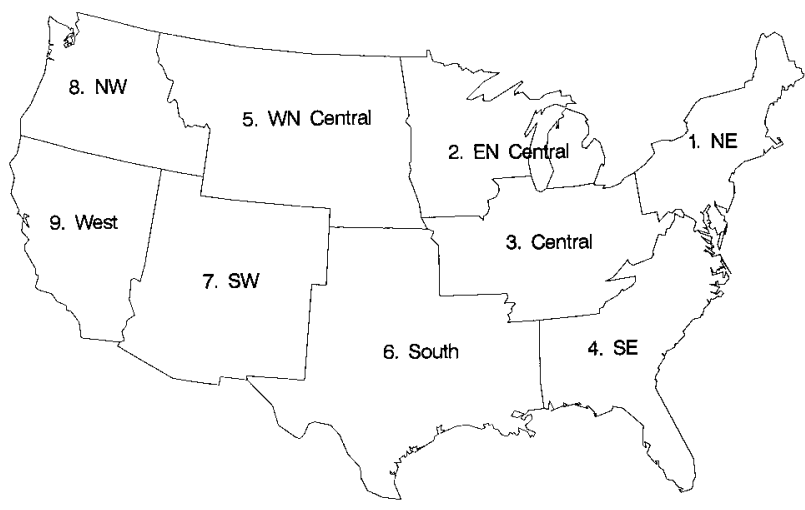

FIG. 4. U.S. climate regions of the 48 contiguous states.

it is convenient to use the nine climate regions shown in Fig. 4, which are defined by the U.S. National Climatic Data Center (NCDC), since much of the relevant climate and weather data are aggregated for those regions. Flood damage per capita for each climate region equals the regional damage divided by the regional population for each year. Tangible wealth estimates for each state are not readily available, so damage per unit wealth is not analyzed at the regional level.

The recent climate literature was surveyed to find precipitation measures frequently used and cited in flood research. ${ }^{8}$ Based on this review, 10 precipitation-related measures were selected:

1) total precipitation (USTP)

2) number of wet days per station (USWET)

3) number of extreme precipitation days ( $>2$ inches) per station (USEXT)

4) number of 2-day heavy precipitation events per station (USHP2)

5) number of 3-day heavy precipitation events per station (USHP3)

6) number of 5-day heavy precipitation events per station (USHP5)

7) number of 7-day heavy precipitation events per station (USHP7)

8) percentage of the conterminous U.S. area with much above-normal cold season (October-April) precipitation (HPCOLD)

9) percentage of the conterminous U.S. area with the number of wet days much above normal (ABNWET)

communication) in the NWS Office of Hydrology, a reanalysis of this data would be required to obtain useful information. We are currently engaged in such reanalysis. The U.S. Army Corps of Engineers data are available online at http://www.usace.army.mil/inet/ functions/cw/cecwe/flood.htm.

${ }^{8}$ We thank Naressa Cofield, of UCAR/SOARS and Alabama A\&M, for assistance with the literature review.
10) percentage of the conterminous U.S. area with much above-normal proportion of total annual precipitation from 1-day extreme events (ABNEXT)

The Illinois State Water Survey provided measures (1)-(7) (K. E. Kunkel 1998, personal communication). Kunkel et al. (1993) describes the methods used to compute the partial-duration time series for measures (4)(7). The NCDC provided measures (8)-(10) (T. R. Karl 1998 , personal communication) that are based on indexes used in Karl et al. (1996).

Note that thresholds for measures (2), (3), and (9) are based on absolute levels of daily precipitation (greater than 0 or 2 in.). In contrast, the thresholds for measures (4)-(8) and (10) are based on precipitation that is unusually high compared to normal amounts at each weather station. In measures (4)-(7) the threshold for "heavy precipitation" is based on a 5-yr recurrence interval; that is, the threshold for a specific station is the $N$-day precipitation amount that is exceeded on average once every $5 \mathrm{yr}$ (for $N=2,3,5$, or 7 , respectively). In measure (8), "much above normal" is defined as being within the upper $10 \%$ of all cold season values at a given station. In measure (10), 1-day extreme events are defined as those in the upper $10 \%$ of daily precipitation amounts at a given station.

Frequency distributions of each data series were tested for normality and, if necessary, data were transformed to best approximate a normal distribution. The three flood damage series were converted to normal distributions using the log transformation, which also serves to stabilize their variance:

$$
\begin{aligned}
\mathrm{D} & =\ln (\text { damage }) \\
\mathrm{DPC} & =\ln (\text { damage per capita }), \\
\mathrm{DPW} & =\ln (\text { damage per unit wealth). }
\end{aligned}
$$

Precipitation measures (1)-(7) and (10) do not deviate significantly from normality, based on the Shapiro-Wilk test. To approximate a normal distribution, measure (8) required a log transformation, and measure (9) required a square root transformation.

The transformed damage series were tested for linear trends. For the national data, 1932-97, Pearson productmoment correlations were computed between all pairs of variables. Stepwise multiple regression was used to identify the precipitation measures that can best predict total damage, damage per capita, and damage per unit wealth. (To determine whether the precipitation measures could adequately account for trends in damage, a linear trend variable was also included in the modeling.) For the nine climate regions, 1983-97, only the first seven of the precipitation measures were available. Correlations of those precipitation measures with total damage and damage per capita were compared between the nine regions. In all tests of statistical significance, a 95\% confidence level was used. 
TABLE 1. Rates of change in flood damage and socioeconomic indicators, 1932-97.

\begin{tabular}{lc}
\hline \hline \multicolumn{1}{c}{ Variable } & $\begin{array}{c}\text { Annual rate } \\
\text { of change }\end{array}$ \\
\hline $\begin{array}{l}\text { Total annual flood damage, adjusted for inflation } \\
\text { Socioeconomic indicators: }\end{array}$ & $+2.92 \% *$ \\
Population & $+1.26 \% *$ \\
Net stock of fixed reproducible tangible wealth & $+3.13 \% *$ \\
$\quad$ (in real \$) & $+1.85 \% *$ \\
Tangible wealth per capita (in real \$) & \\
Flood damage adjusted for socioeconomic indicators: & $+1.65 \% *$ \\
Flood damage per capita & $-0.49 \%$ \\
Flood damage per million \$ tangible wealth & \\
$\quad$ (in current \$) &
\end{tabular}

* Statistically significant $(\alpha=0.05)$.

\section{Results}

a. Trends in national flood damage, population, and wealth

While national total flood damage varies a great deal from year to year, there is a statistically significant increasing trend averaging 2.92\% $\mathrm{yr}^{-1}$ from 1932 to 1997. (A linear trend in D converts into an exponentially increasing trend in damage, as show in Fig. 1). ${ }^{9}$ Surprisingly, neither researchers nor policy makers well understand this trend even though reversing it is a cornerstone objective of national flood policy. For instance, the U.S. government's Interagency Floodplain Management Review Committee (IFMRC 1994) and the Association of State Flood Plain Managers (www.asfpm.org) both hold as policy goals the objective of reducing the total amount of national flood damage.

Table 1 compares the rate of increase in flood damage with rates of increase in population and wealth during the same time period. The U.S. population has grown

\footnotetext{
${ }^{9}$ The period 1932-97 was selected because of limitations in the precipitation data used in the analysis. In any case, pre-1930 damage data are likely to suffer from the most errors and thus would not be used (cf. White et al. 1958).
}

at a rate of $1.26 \% \mathrm{yr}^{-1}$; thus, under an assumption that population in flood-prone areas has grown at the same rate, then $43 \%$ of the increase in flood damage can be attributed to population growth. Figure $3 \mathrm{a}$ shows the increasing trend in flood damage per capita: the annual rate of change is $1.65 \% \mathrm{yr}^{-1}$ (Table 1 ).

The nation's net stock of fixed reproducible tangible wealth (in 1995 dollars) has grown at a rate of $3.13 \%$ $\mathrm{yr}^{-1}$, slightly more rapidly than flood damage. As a result, flood damage per unit wealth appears to have decreased slightly, although the trend is statistically insignificant (Table 1, Fig. 3b). Assuming that the nation's wealth in flood-prone areas has grown at the same rate as national wealth, then all of the increase in flood damage can be attributed to the growth in national wealth.

The three different measures of flood damage-absolute, per capita, and per unit wealth-each lead to different conclusions about the nature of the flood problem. For instance, there are three interpretations as to the "worst" year for flood damage. Total flood damage adjusted only for inflation (Fig. 1) was highest in 1993. However, flood damage per capita (Fig. 3a) was highest in 1972 (at \$68.33 per U.S. resident, edging out 1993 when the damage amounted to $\$ 66.61$ per resident). Furthermore, as a proportion of the nation's tangible wealth (Fig. 3b), flood damage was highest in 1937, when it amounted to $\$ 1453$ for each $\$ 1 \times 10^{6}$ of tangible wealth (1972 is in second place, while 1993 drops to fifth place). If policy makers evaluate national flood policy by outcomes, than the choice of evaluation metric could determine adjudication of success or failure.

\section{b. Statistical modeling of flood damage and precipitation}

\section{1) NAtional Results}

Intercorrelations between the precipitation measures and a linear trend variable (YEAR) are shown in Table 2. All pairs of precipitation measures are significantly correlated. All of the precipitation measures except ABNWET (9) are positively correlated with YEAR, in-

TABLE 2. Correlations between precipitation-related measures, 1932-97.

\begin{tabular}{|c|c|c|c|c|c|c|c|c|c|c|}
\hline & USTP & USWET & USEXT & USHP2 & USHP3 & USHP5 & USHP7 & $\ln (\mathrm{HPCOLD})$ & sqrt(ABNWET) & ABNEXT \\
\hline USWET & 0.91 & & & & & & & & & \\
\hline USEXT & 0.84 & 0.65 & & & & & & & & \\
\hline USHP2 & 0.56 & 0.55 & 0.60 & & & & & & & \\
\hline USHP3 & 0.57 & 0.54 & 0.61 & 0.96 & & & & & & \\
\hline USHP5 & 0.60 & 0.60 & 0.57 & 0.91 & 0.94 & & & & & \\
\hline USHP7 & 0.62 & 0.61 & 0.59 & 0.86 & 0.89 & 0.94 & & & & \\
\hline $\ln (\mathrm{HPCOLD})$ & 0.64 & 0.59 & 0.48 & 0.37 & 0.37 & 0.36 & 0.36 & & & \\
\hline sqrt(ABNWET) & 0.77 & 0.80 & 0.54 & 0.38 & 0.36 & 0.40 & 0.46 & 0.62 & & \\
\hline ABNEXT & 0.93 & 0.79 & 0.88 & 0.64 & 0.65 & 0.64 & 0.66 & 0.60 & 0.68 & \\
\hline YEAR & 0.33 & 0.48 & 0.31 & 0.32 & 0.29 & 0.30 & 0.26 & 0.25 & $0.15^{*}$ & 0.34 \\
\hline
\end{tabular}

$*$ This is the only correlation that is not significantly different from zero $(\alpha=0.05)$. 
TABLE 3. Correlations of flood damage measures, $\mathrm{D}=\ln$ (damage), DPC $=\ln$ (damage per capita) and DPW $=\ln ($ damage per unit wealth), with precipitation measures, 1932-97.

\begin{tabular}{|c|c|c|c|c|c|c|c|}
\hline Predictor & Variable name & $\begin{array}{l}\text { Corre- } \\
\text { lation } \\
\text { with } D\end{array}$ & $\begin{array}{l}\text { Corre- } \\
\text { lation } \\
\text { with DPC }\end{array}$ & $\begin{array}{l}\text { Corre- } \\
\text { lation } \\
\text { with DPW }\end{array}$ & $\begin{array}{c}R^{2} \\
\text { with } \\
D\end{array}$ & $\begin{array}{c}R^{2} \\
\text { with } \\
\text { DPC }\end{array}$ & $\begin{array}{c}R^{2} \\
\text { with } \\
\text { DPW }\end{array}$ \\
\hline Total precipitation & USTP & $0.477 *$ & $0.449 *$ & $0.328 *$ & 0.228 & 0.202 & 0.108 \\
\hline Number of wet days per station & USWET & $0.517 *$ & $0.455^{*}$ & $0.271 *$ & 0.267 & 0.207 & 0.073 \\
\hline Number of extreme precipitation days ( $>2$ in.) per station & USEXT & $0.391 *$ & $0.361 *$ & $0.247 *$ & 0.153 & 0.130 & 0.061 \\
\hline Number of 2-day heavy events per station & USHP2 & $0.507 *$ & $0.484 *$ & $0.384 *$ & 0.257 & 0.234 & 0.147 \\
\hline Number of 3-day heavy events per station & USHP3 & $0.441 *$ & $0.419 *$ & $0.327 *$ & 0.194 & 0.176 & 0.107 \\
\hline Number of 5-day heavy events per station & USHP5 & $0.495^{*}$ & $0.475^{*}$ & $0.379 *$ & 0.245 & 0.226 & 0.144 \\
\hline Number of 7-day heavy events per station & USHP7 & $0.425 *$ & $0.407 *$ & $0.320 *$ & 0.181 & 0.166 & 0.102 \\
\hline $\begin{array}{l}\text { Percent of conterminous U.S. area with much above normal } \\
\text { cold season (Oct-Apr) precipitation. }\end{array}$ & $\ln (\mathrm{HPCOLD})$ & $0.305^{*}$ & $0.279 *$ & 0.177 & 0.093 & 0.078 & - \\
\hline $\begin{array}{l}\text { Percent of conterminous U.S. area with number of wet days } \\
\text { much above normal }\end{array}$ & $\operatorname{sqrt}(A B N W E T)$ & $0.340 *$ & $0.339 *$ & $0.280^{*}$ & 0.116 & 0.115 & 0.078 \\
\hline $\begin{array}{l}\text { Percent of conterminous U.S. area with much above-normal } \\
\text { proportion of total annual precipitation from 1-day extreme } \\
\text { events }\end{array}$ & ABNEXT & $0.457^{*}$ & $0.425^{*}$ & $0.298^{*}$ & 0.209 & 0.181 & 0.089 \\
\hline Linear trend & YEAR & $0.501 *$ & $0.312 *$ & -0.096 & 0.251 & 0.097 & - \\
\hline
\end{tabular}

* Significantly different from zero $(\alpha=0.95)$.

dicating significant upward trends during 1932-97. In most, the trend is small relative to overall variability (explaining less than $12 \%$ of the variance); however, the trend in the number of wet days per station (USWET) is more pronounced (explaining nearly 23\% of the variance).

Table 3 presents the correlations of D, DPC, and DPW with the precipitation measures and linear trend variable. For D and DPC, all of the correlations are statistically significant at a $95 \%$ confidence level. For DPW, the correlations with all precipitation measures except HPCOLD (8) are significant. Here D is most highly correlated with the number of wet days per station. Both DPC and DPW are most highly correlated with 2-day and 5-day heavy precipitation events, with 2-day events showing a slightly stronger relationship.

Stepwise multiple regression was used to determine whether several predictors could be used together to better explain the variability in D, DPC, and DPW. The

TABLE 4. Multivariate models of flood damage measures, identified by stepwise regression on precipitation measures and a linear trend variable, 1932-97.

\begin{tabular}{|c|c|c|c|c|}
\hline Predictor & $\begin{array}{c}\text { Parameter } \\
\text { estimate }\end{array}$ & $\begin{array}{l}\text { Standard } \\
\text { error }\end{array}$ & $t$ & Prob $>t$ \\
\hline \multicolumn{5}{|c|}{$\begin{array}{l}\text { Dependent variables: } D=\ln (\text { damage }), R^{2}=0.386 \text {, adjusted } R^{2}= \\
0.366\end{array}$} \\
\hline USHP2 & 9.867 & 2.658 & 3.712 & 0.0004 \\
\hline YEAR & 0.022 & 0.006 & 3.634 & 0.0006 \\
\hline \multicolumn{5}{|c|}{$\begin{array}{l}\text { Dependent variable: } \mathrm{DPC}=\ln (\text { damage per capita }), R^{2}=0.285 \text {, ad } \\
\text { justed } R^{2}=0.262\end{array}$} \\
\hline USHP2 & 7.797 & 2.970 & 2.625 & 0.0109 \\
\hline USWET & 0.049 & 0.023 & 2.118 & 0.0382 \\
\hline \multicolumn{5}{|c|}{$\begin{array}{l}\text { Dependent variable: } \mathrm{DPW}=\ln (\text { damage per unit wealth }), R^{2}=0.200 \\
\text { adjusted } R^{2}=0.175\end{array}$} \\
\hline USHP2 & 10.274 & 2.649 & 3.878 & 0.0003 \\
\hline YEAR & -0.012 & 0.006 & -2.036 & 0.0460 \\
\hline
\end{tabular}

resulting "best" models each contained two significant predictors, as shown in Table 4.

For total damage, the best model of D includes the number of 2-day heavy precipitation events (USHP2) and the trend variable (YEAR). Together, these two predictors provide a better fit than any model containing the number of wet days per station (USWET), which is the most highly correlated single predictor. The two predictors explain $38.6 \%$ of the variance in D. Because the two predictors are intercorrelated, only $13.5 \%$ of the variance in $\mathrm{D}$ can be uniquely attributed to 2-day heavy precipitation events (USHP2) and $12.9 \%$ to linear trend. The remaining $12 \%$ could be attributable to either predictor.

For per capita damage, the best model of DPC depends upon both the number of 2-day heavy precipitation events (USHP2) and the number of wet days per station (USWET). The two predictors explain $28.5 \%$ of the variance in per capita damage. (Using adjusted $R^{2}$ to control for the number of predictors in the model indicates that $26.2 \%$ of the variance would be explained in independent data.) No significant linear trend remains in the residuals of this model. These results are consistent with a hypothesis that the upward trend in DPC can be entirely explained by the concurrent trend in precipitation. The time series of USHP2 and USWET are shown with the per capita damage in Fig. 5.

For damage per unit wealth, the best model of DPW combines the number of 2-day heavy precipitation events (USHP2) with the trend variable (YEAR). None of the other precipitation measures significantly improves the model. Furthermore, the trend coefficient is negative, implying that there is a significant decreasing trend in damage per unit wealth after controlling for the number of 2-day heavy precipitation events. The model explains $20.0 \%$ of the variance. (The adjusted $R^{2}$ indicates that $17.5 \%$ of the variance in damage per unit wealth would be explained in independent data.) 
(a) U.S. Per Capita Flood Damage (bars)

and 2-day Heavy Precipitation Events (solid line)

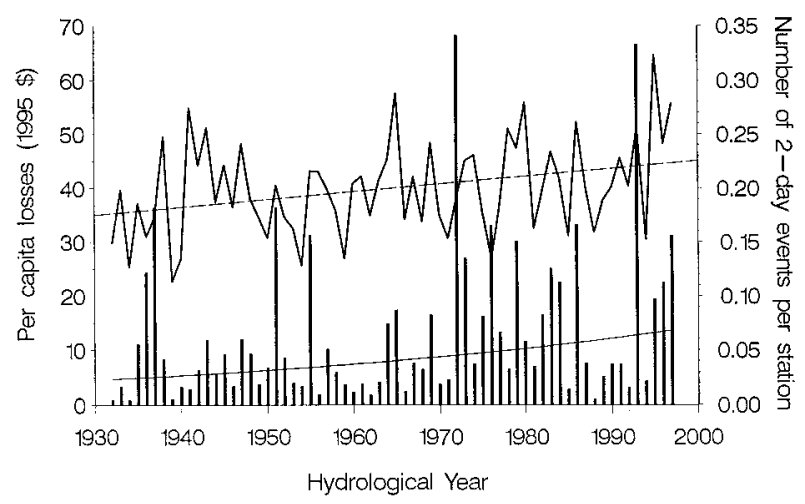

(b) U.S. Per Capita Flood Damage (bars)

and Number of Wet Days (solid line)

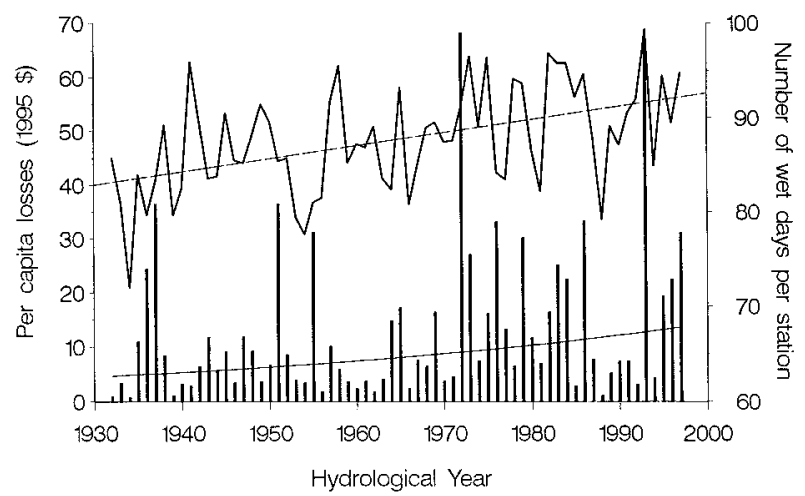

FIG. 5. (a) Two-day precipitation events superimposed on Fig. 3a, per capita damage. (b) Number of wet days superimposed on Fig. 3a, per capita damage.

\section{2) RegionAl anALysis}

The frequency and severity of damaging floods varies greatly across the United States, determined by local geography, climate, and development. Table 5 shows statistics related to flood damage in each climate region during 1983-97. The region with the highest population (region 1 northeast) is among the lowest in total flood losses. The region with the highest annual precipitation (region 4 southeast) also is among the lowest in total flood losses. The climate regions with the highest total flood losses during 1983-97 are region 6 (south), region 2 (east north central), and region 3 (central), with losses of $\$ 15.2$ billion, $\$ 11.8$ billion, and $\$ 11.4$ billion, respectively-flooding dominated by the Mississippi River and its tributaries. The highest losses per capita are in sparsely populated region 5 (west north central), with annual damage averaging more than $\$ 90$ per person.

Flood losses for each year are shown in Fig. 6 for the four climate regions that encompass most of the vast Mississippi-Missouri River system (region 2 east north central, region 3 central, region 5 west north central, and region 6 south). The sporadic nature of major flood events is evident in these graphs. Extremely costly floods occurred most frequently in the lower Mississippi basin of region 6, particularly in Louisiana. Damage in regions 2 and 3 is dominated by the great flood of 1993 (Changnon 1996).

Seven of the precipitation-related measures that we used in the analysis of national flood damage are available for the climate regions during 1983-97. They are

1) total precipitation (TP)

2) number of wet days per station (WET)

3) number of extreme precipitation days ( $>2$ in.) per station (EXT)

4) number of 2-day heavy precipitation events per station (HP2)

5) number of 3-day heavy precipitation events per station (HP3)

6) number of 5-day heavy precipitation events per station (HP5)

7) number of 7-day heavy precipitation events per station (HP7)

Total flood damage (in millions of 1995 dollars) for each climate region, $c$, was converted to approximately normal distributions using the log transformation

$$
\mathrm{D}_{c}=\ln (\text { damage }+0.1) \text {. }
$$

TABLE 5. Precipitation and flood damage in U.S. climate regions, 1983-97.

\begin{tabular}{|c|c|c|c|c|c|c|}
\hline Climate region & States & $\begin{array}{l}\text { Population } \\
\text { in } 1990 \\
\left(\times 10^{6}\right)\end{array}$ & $\begin{array}{c}\text { Rate of } \\
\text { population } \\
\text { growth } \\
\text { 1983-97 (\%) }\end{array}$ & $\begin{array}{l}\text { Mean annual } \\
\text { precipitation } \\
\text { 1983-97 (in.) }\end{array}$ & $\begin{array}{c}\text { Total flood } \\
\text { losses 1983-97 } \\
\text { (billion 1995\$) }\end{array}$ & $\begin{array}{c}\text { Mean annual } \\
\text { damage per } \\
\text { capita }(1995 \$)\end{array}$ \\
\hline Northeast (1) & $\begin{array}{c}\text { CT, DE, DC, ME, MD, MA, } \\
\text { NH, NJ, NY, PA, RI, VT }\end{array}$ & 56.9 & 0.37 & 42.9 & 3.094 & 3.65 \\
\hline East north central (2) & IA, MI, MN, WI & 21.3 & 0.62 & 31.7 & 11.791 & 36.11 \\
\hline Central (3) & IL, IN, KY, MO, OH, TN, WV & 43.3 & 0.45 & 44.3 & 11.410 & 17.28 \\
\hline Southeast (4) & $\mathrm{AL}, \mathrm{FL}, \mathrm{GA}, \mathrm{NC}, \mathrm{SC}, \mathrm{VA}$ & 39.8 & 1.64 & 51.8 & 3.475 & 5.90 \\
\hline West north central (5) & $\mathrm{MT}, \mathrm{NE}, \mathrm{ND}, \mathrm{SD}, \mathrm{WY}$ & 4.2 & 0.20 & 17.5 & 5.925 & 90.94 \\
\hline South $(6)$ & $\mathrm{AR}, \mathrm{KS}, \mathrm{LA}, \mathrm{MS}, \mathrm{OK}, \mathrm{TX}$ & 31.8 & 0.88 & 38.0 & 15.153 & 31.44 \\
\hline Southwest (7) & $\mathrm{AZ}, \mathrm{CO}, \mathrm{NM}, \mathrm{UT}$ & 10.2 & 2.09 & 14.8 & 3.019 & 20.61 \\
\hline Northwest (8) & ID, OR, WA & 8.7 & 1.85 & 27.5 & 4.459 & 30.59 \\
\hline West (9) & $\mathrm{CA}, \mathrm{NV}$ & 31.0 & 1.89 & 17.1 & 6.078 & 12.87 \\
\hline
\end{tabular}


5. WN Central

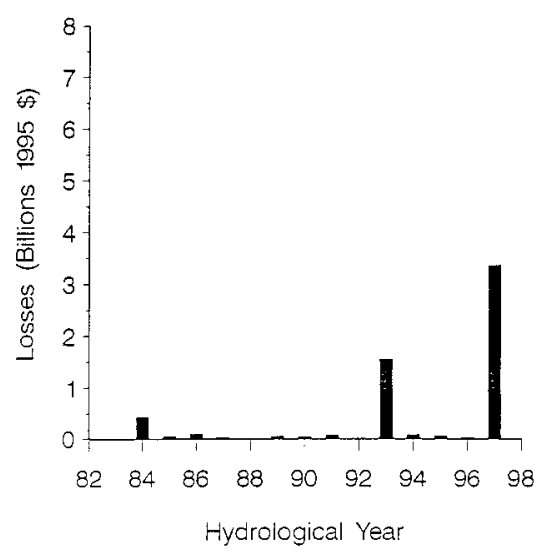

6. South

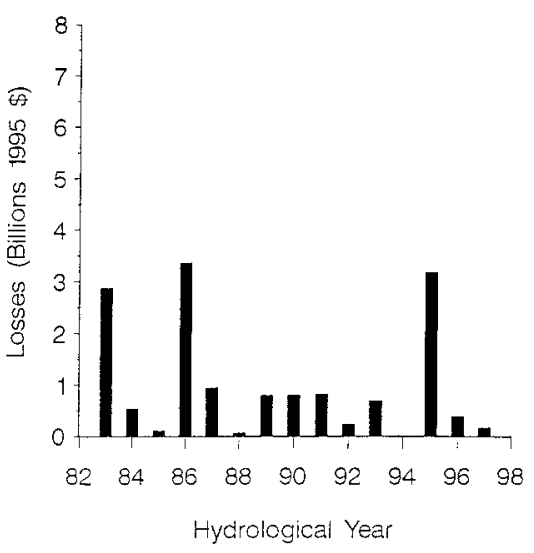

2. EN Central

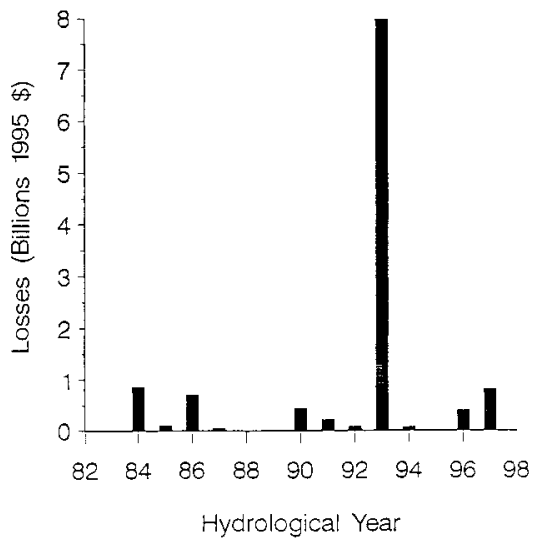

3. Central

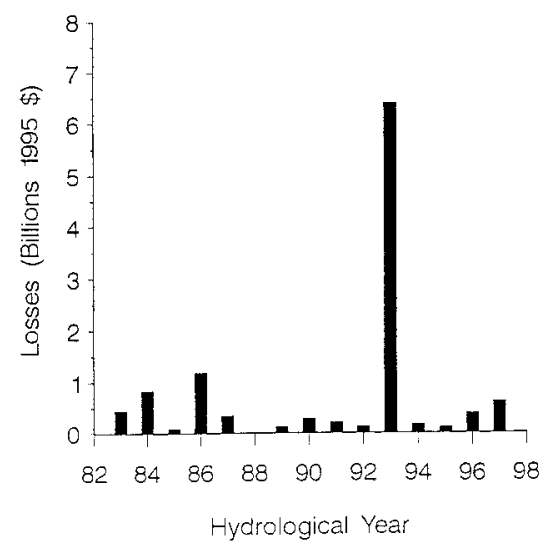

FIG. 6. Flood damage in the Mississippi River basin. Figures are arranged to correspond to geographic climate division locations.

Similarly, damage per capita (in 1995 dollars) was converted using the transformation

$$
\mathrm{DPC}_{c}=\ln (\text { damage per capita }+0.1) .
$$

In each case, the constant 0.1 is included to allow for the rare years in which a region had no reported damage. (This occurred once in region 5 and twice in region 9.)

TABLE 6. Highest correlations, by region, of flood damage measures $D_{c}$ and $\mathrm{DPC}_{c}$ with precipitation measures, $1983-97$.

\begin{tabular}{|c|c|c|c|c|c|c|}
\hline \multirow[b]{2}{*}{ Region, $c$} & \multicolumn{3}{|c|}{$D_{c}$} & \multicolumn{3}{|c|}{$\mathrm{DPC}_{c}$} \\
\hline & Measure & Corr. & $R^{2}$ & Measure & Corr. & $R^{2}$ \\
\hline Northeast (1) & HP3 & $0.67 *$ & 0.449 & HP3 & $0.77 *$ & 0.593 \\
\hline East north central (2) & WET & $0.59 *$ & 0.348 & WET & $0.64 *$ & 0.410 \\
\hline Central (3) & HP2 & $0.74 *$ & 0.548 & $\mathrm{HP} 2$ & $0.73 *$ & 0.533 \\
\hline Southeast (4) & HP7 & 0.47 & - & HP7 & 0.45 & - \\
\hline West north central (5) & WET & $0.64 *$ & 0.410 & WET & $0.65 *$ & 0.423 \\
\hline South (6) & HP2 & $0.72 *$ & 0.518 & HP2 & $0.73 *$ & 0.533 \\
\hline Southwest (7) & HP2 & $0.58 *$ & 0.336 & HP7 & $0.64 *$ & 0.410 \\
\hline Northwest (8) & EXT & $0.82 *$ & 0.672 & EXT & $0.82 *$ & 0.672 \\
\hline West (9) & EXT & $0.71 *$ & 0.504 & EXT or TP (tied) & $0.78^{*}$ & 0.608 \\
\hline
\end{tabular}

* Significantly different from zero $(\alpha=0.05)$. 
The precipitation measures most strongly correlated with $D_{c}$ and $\mathrm{DPC}_{c}$ within each climate region are shown in Table $6 .{ }^{10}$ In all regions except region 4 (southeast), the correlations are statistically significant at a $95 \%$ confidence level. Because region 3 (central) and region 6 (south) are downstream in the Mississippi River system, damage in those regions was also tested for correlation with precipitation measures from the upstream regions 2 and 5. Damage in region 3 was found to be more highly correlated with WET5 (the number of wet days per station in region 5) than with any region 3 measures: for $D_{3}$ and WET5 $r=0.85$ and $R^{2}=0.72$, for $\mathrm{DPC}_{3}$, $r=0.84$ and $R^{2}=0.71$. Thus, flood damage in region 3 (central) appears to be influenced by precipitation a considerable distance away.

\section{Discussion}

\section{a. Population, wealth, and exposure to damaging floods}

The three models: total damage, damage per capita, and damage per unit wealth, provide different ways of viewing exposure to damaging floods, which lead to differing conclusions. Total $D$ is not adjusted for exposure, therefore models of $D$ consider exposure only through the inclusion of a linear trend variable. The linear trend variable is significant, after controlling for precipitation, indicating that precipitation alone is not sufficient to explain the increasing trend in national flood damage. However, models of $D$ provide little explanatory power, because there are so many possible causes of a linear trend.

If population growth is similar in flood-prone and non-flood-prone areas, then the models of DPC are appropriate. The linear trend in DPC is substantially less than that in $D$, and the best model suggests that the trend in DPC can be explained entirely by a concurrent upward trend in precipitation. This would imply that the upward trend in total damage during 1932-97 could be attributed to population growth and increased precipitation.

If rates of growth in tangible wealth are similar in flood-prone and non-flood-prone areas, then the models of DPW are appropriate. There is no significant trend in DPW during 1932-97, despite the fact that precipitation has increased. In the best model of DPW, after the variability in precipitation is accounted for, a significant decreasing trend is found in damage per unit wealth. This would suggest that the vulnerability of tangible property to flood damage has declined (perhaps because of successful flood policies), and the total damage has increased simply because of growth in total wealth. It should be noted that the models of DPW are

\footnotetext{
${ }^{10}$ In most regions, correlations with one or two other precipitation measures are nearly as high as those shown.
}

the poorest-fitting models in this study (explaining a maximum of $20 \%$ of the variance in DPW).

It is impossible, with the present data, to determine which of these models best approximates reality. Indeed, it is likely that population growth and wealth each play an integral role in explaining flood damage, but present data do not allow for such a combined assessment. The models do indicate that societal factors play a large role in explaining overall trends in flood damage. The models of DPC appear most plausible because they show the strongest relationship to precipitation and leave no unexplained linear trend.

\section{b. Evaluation of the precipitation measures}

Figures 1 and 3 show that trends account for only a small part of the year-to-year variability in flood damage. Variability in damage depends on variations in the location, amount, timing, and intensity of precipitation. ${ }^{11}$ The ten precipitation measures, examined using national and regional data, emphasize similar features of precipitation that may influence the likelihood of flooding. This suggests that climatologists may wish to consider dimensions of precipitation other than amounts to more closely link climate variations with damage.

In these data, heavy precipitation events with a duration of several days show the strongest relationship with flood damage, both for the nation as a whole and for five of the nine climate regions. Note that correlations between the precipitation measures are relatively high and that differences in the correlation with damage are small for some of the measures. It is possible that other measures would be the most highly correlated in different data samples. The results provide insight as to how climatologists might measure "intense", or "heavy" precipitation as it relates to damaging floods. The 2- to 7-day heavy precipitation events [measures (4)-(7)] are not based on an absolute amount of rainfall, but are defined relative to precipitation amounts at each location. In contrast, measure (3), based on a fixed threshold of 2 or more in. of rainfall, is much less strongly related to flood damage for the nation as a whole. Only in two of the climate regions (region 8 northwest and region 9 west) was the 2 -in. threshold most highly correlated with damage. This suggests that contextual measures of precipitation amount, based on distributions for each local area, may be more generally appropriate than absolute precipitation thresholds.

The number of wet days per station emerges as a second predictor in the model for DPC, supplementing the information provided by 2-day heavy events. Local wet days are the best predictor of damage in two of the climate regions, while wet days in region 5 are the best

\footnotetext{
${ }^{11}$ In a subsequent analysis, we are investigating the relationship of the El Niño-Southern Oscillation (ENSO) cycle, precipitation, and flood damage.
} 
predictor of damage in region 3 . Therefore, the frequency of rainy or snowy days appears to be a significant factor in damaging floods.

In all three models of nationwide damage, the multiple $R^{2}$ values are low-a great deal of unexplained variance remains. The regional $R^{2}$ values are substantially higher, indicating the importance of studying damaging floods on smaller spatial scales. Local factors, both social and weather-related, must be taken into account in explaining the damage inflicted by floods.

\section{Conclusions}

The analysis presented in this paper leads to the following conclusions and hypotheses.

\section{a. Precipitation measures most closely related to variability in flood damages}

At a national level, of the 10 precipitation measures examined in this study, the ones most closely related to damaging floods are the number of 2-day heavy rainfall events and the number of wet days. Heavy rainfall events are defined contextually (relative to local incidence of rainfall), not as absolute thresholds. However, because many of the measures of precipitation are highly correlated other measures show a statistically significant relationship with damaging floods (but explain less variance). The 2-in. (>50.4 $\mathrm{mm})$ rainfall threshold is among the least well correlated with damaging floods (except in the two western regions).

This study suggests that even though there is a strong relationship between precipitation and flood damageas might be expected-there is a considerable amount of variance left unexplained. Some of the unexplained variance is the result of nonlinearity in the relationship: once a threshold (context-specific) is exceeded, damage can increase abruptly to catastrophic levels, as in the case of the 1993 flood on the upper Mississippi River system. This underscores the need for scientists and policy makers to be careful when discussing "trends" in climate and climate-related impacts, particularly given the apparent nonstationarity of the underlying conditioning factors. Further work on the dimensions of precipitation other than amount, for example, rates, location, timing, etc. (e.g., Trenberth 1999) might lead to improved connections of climatic factors with societal impacts.

\section{b. National flood policy}

The study indicates that the growth in recent decades in total damage is related to both societal factors and climate factors. This suggests that much of the floodrelated damage in recent decades is the result of numerous human choices, and raises the possibility that society has considerable remaining potential to reduce its vulnerability to floods. Whether or not such steps make practical, political, or economic sense depends on how the nation's flood problem is defined. Depending upon the measure used to assess flood damage, one can arrive at opposite views of the nature of the problem. For instance, while total flood losses increased dramatically, in terms of national wealth flood losses have not changed significantly over recent decades. Whether or not existing flood policies have reduced or enhanced vulnerability goes beyond the scope of this study.

\section{c. Global climate policy}

The study shows clearly that increased precipitation is associated with increased flood damage. Similarly, increasing population growth and wealth are also associated with increased total flood damage. Much of the variance in damage is not explained by the statistical models and is likely to depend on local differences of climate and policy. For example, whether a given increase in precipitation leads to increased hydrologic flooding will depend on its geographical distribution and timing, and whether population growth leads to increased flood damage depends on whether and how the growth occurs within the flood plain. ${ }^{12}$

Looking to the future even without an increase in precipitation, total flood damage will continue to increase with the nation's growing population and wealth-unless actions are taken to reduce flood vulnerability. This is consistent with the findings of a 1993 Congressional Office of Technology Assessment report (OTA 1993). The findings are also consistent with those who argue that the greatest potential for reducing flood losses is for policy makers to continue to focus attention on flood plain management, rather than on seeking to prevent future floods by modifying (or stabilizing) the climate. $^{13}$

With respect to the relative contribution of climate and societal factors to the flood damage record, Trenberth's (1997) metaphor of increasing precipitation being the "straw that breaks the camel's back" is particularly apt. The camel (representing society) is already burdened by the weight of past decisions that have placed people and property into harm's way. Thus, when hydrologic floods do occur, they can lead to enormous damage. In many instances, such damage is avoidablesociety need not wait for the "last straw" to act.

At the regional level, this study reports a stronger relationship between precipitation and flood damage

\footnotetext{
${ }^{12}$ In addition, our analysis provides supporting evidence for the notion that increasing U.S. precipitation documented by Karl and colleagues has not led to a corresponding increase in the highest levels of streamflow documented by Lins and Slack. See Pielke and Downton (1999) for discussion.

13 There are important reasons why climate mitigation makes sense, however, reducing flood damages does not seem to be foremost among them. See Pielke (1998) for discussion of mitigation and adaptation responses to climate change.
} 
than at the national level (although the smaller samples imply greater uncertainty as well). The findings also suggest that context matters, as different types of precipitation are most closely related to damage in different regions. This raises the possibility that what might be damaging precipitation in one region could be innocuous or even beneficial in another region (cf. Garcia et al. 1990). Further, understanding the societal impacts of a change in the hydrologic cycle is perhaps more complicated than was once thought. Not only are the impacts of precipitation on damaging floods contextual, but there are likely to be trade-offs with other impact areas since the impacts of precipitation on society and environment go well beyond damaging floods to include issues related to ecosystem health, water resources, and water quality (among others). It is conceivable that a full understanding of the integrated impacts of a change in the hydrologic cycle is beyond scientists' ability to accurately predict. This supports the notion of giving more attention to problem- and region-specific aspects of climate change (cf. Rayner and Malone 1998).

\section{d. Future research}

Reliable and accurate knowledge of the science of flood climatology, hydrology, and meteorology is important because it plays a role in many policy decisions, including land use, insurance, and the allocation of finite public resources. Yet, in spite of the large and growing impacts of floods on society, most discussion of the science and policy of floods is characterized by unexamined assumptions and imprecise language — not a recipe for the translation of science into effective policies. The analysis presented here is but a first step toward an improved understanding of the relation of the hydrologic cycle and damaging floods. Much additional research is needed to further develop this understanding. Among the issues that remain:

- Studies of damage will be more closely related to precipitation and stream flow if they are conducted at the basin level. This presents a need for damage data recorded at local scales. Given the contextuality of precipitation impacts, there is also a need to understand precipitation (both observed and modeled) at scales most closely related to damage.

- More extensive damage data, particularly at state, local, or watershed levels would allow for a longer time series analysis of regional impacts. The NWS has in its records data that might allow for such detail.

- Further analysis of flood damage is needed to better understand the dynamics of damaging floods. The many small- and moderate-sized losses are dominated in the flood record by the occasional catastrophic event, suggesting a nonlinearity that might have societal or policy causes.

- It would be of use to conduct similar further analyses in other regions of the world where there exist reliable records of precipitation and flood damage. This would help to confirm or deny some of the hypotheses raised by this study.

- There remains a significant lack of knowledge of the effectiveness of national flood policies on the trends in flood damage and societal vulnerability to floods. Systematic evaluations of national flood policies are long overdue.

In conclusion, the relationship of climate, hydrology, and society in producing damaging floods is complex and not fully understood. Nonetheless, so long as policy makers seek to reduce flood damage, there will be a need to understand the relationship between climate variations and various societal factors in the damage that is observed. This study suggests that climate plays an important, but by no means determining role in the growth in flood damage in the United States in recent decades. This should provide optimism to decision makers seeking to reduce vulnerability to floods, as it suggests that local actions can have a significant effect, independent of the climate variations of the future.

Acknowledgments. We received valuable comments on an earlier draft from Stan Changnon, Tom Karl, Rick Katz, Ken Kunkel, Harry Lins, Michael MacCracken, Mary Fran Myers, Eugene Stakhiv, and two anonymous reviewers. We thank the National Climatic Data Center and the Illinois State Water Survey for providing precipitation data and the National Weather Service for providing the damage data. Naressa Cofield (Alabama A\&M) capably assisted with literature review and figure production. We thank D. Jan Stewart for assistance in production of the manuscript. All errors in the text are the responsibility of the authors.

\section{REFERENCES}

Baker, V. R., 1998: Hydrological understanding and societal action. J. Amer. Water Res. Assoc., 34, 819-825.

Chandler, T. J., R. U. Cooke, and I. Douglas, 1976: Physical problems of the urban environment. Geogr. J., 142, 57-80.

Changnon, S. A., 1980: Removing the confusion over droughts and floods: The interface between scientists and policy makers. Water Int., 5, 10-18.

_, Ed., 1996: The Great Flood of 1993: Causes, Impacts, and Responses. Westview Press, 332 pp.

_ 1998: Comments on "Secular trends of precipitation amount, frequency, and intensity in the United States." Bull. Amer. Meteor. Soc., 79, 2550-2552.

_, and M. Demissie, 1996: Detection of changes in streamflow and floods resulting from climate fluctuations and land use-drainage changes. Climatic Change, 32, 411-421.

Coyle, K., 1993: River tinkering worsened flooding. USA Today, 14 July, p. 13A.

FEMA, 1997: Multi-Hazard Identification and Risk Assessment: The Cornerstone of the National Mitigation Strategy. Federal Emergency Management Agency, 369 pp.

Garcia, P., S. A. Changnon, and M. Pinar, 1990: Economic effects of precipitation enhancement in the Corn Belt. J. Appl. Meteor., 29, 63-75.

Hamburger, T., 1997: Floods renew interest in climate changes: Is 
global warming causing more precipitation? Minneapolis StarTribune, 29 April, p. 13A.

Holliday, W. C., J. L. Floyd, and P. T. Chao, 1998: Policy study on impediments to evaluation and development of non-structural flood damage reduction measures. Report from Institute for Water Resources to U.S. Army Corps of Engineers, 84 pp. [Available from U. S. Army Corps of Engineers, Water Resources Support Center, Institute for Water Resources, Casey Building, Alexandria, VA 22301.]

Hoyt, W., and W. B. Langbein, 1955: Floods. Princeton University Press, $469 \mathrm{pp}$

IFMRC, 1994: A blueprint for change-Sharing the challenge: Floodplain management into the 21 st century. Report of the Interagency Floodplain Management Review Committee to the Administration Floodplain Management Task Force, 191 pp.

IFRCRCS, 1997: World Disasters Report 1997. Oxford University Press, $173 \mathrm{pp}$.

IPCC, 1996a: Climate Change 1995: The Science of Climate Change. Cambridge University Press, $572 \mathrm{pp}$.

— 1996b: Climate Change 1995: Economic and Social Dimensions of Climate Change. Cambridge University Press, $448 \mathrm{pp}$.

Karl, T. R., and R. W. Knight, 1998: Secular trend of precipitation amount, frequency, and intensity in the United States. Bull. Amer. Meteor. Soc., 79, 231-242.

,-- D. D. Easterling, and R. G. Quayle, 1995: Trends in U.S. climate during the twentieth century. Consequences, 1, 3-12.

— - — D. R. Easterling, and R. G. Quayle, 1996: Indices of climate change for the United States. Bull. Amer. Meteor. Soc., 77, 279-292.

Kerwin, K., and J. B. Verrengia, 1997: Rare storm loosed Fort Collins flood: Hazard experts say deluge should serve as "wake-up call" for growing population. Rocky Mountain News, 3 August, p. 48A.

Kunkel, K. E., S. A. Changnon, and R. T. Shealy, 1993: Temporal and spatial characteristics of heavy-precipitation events in the Midwest. Mon. Wea. Rev., 121, 858-866.

—, R. A. Pielke Jr., and S. A. Changnon, 1999: Temporal fluctuations in weather and climate extremes that cause economic and human health impacts: A review. Bull. Amer. Meteor. Soc., 80, 1077-1098.

Labaton, S., 1993: U.S. is considering a "revolution" in flood control. New York Times, 28 August, p. 6.

Lins, H. F., and J. R. Slack, 1999: Streamflow trends in the United States. Geophys. Res. Lett., 26, 227-230.

Moser, D. A., 1994: Assessment of the economic effects of flooding. Coping with Floods, G. Rossi, H. Harmancioglu, and V. Yevjevich, Eds., Kluwer Academic, 515-528.

NOAA, 1997: As global climate warms, more floods are expected. Press release 97-3, 2 pp.

OTA, 1993: Preparing for an Uncertain Climate. Vol. 1. U.S. Government Printing Office, 359 pp.

Pielke, R. A., Jr., 1996: Midwest Flood of 1993: Weather, Climate, and Societal Impacts. ESIG/NCAR, 159 pp.
- 1998: Rethinking the role of adaption in climate policy. Global Environ. Change, 8, 159-170.

1999: Nine fallacies of floods. Climatic Change, 42, 413-438. , 2000: Flood impacts on society: Damaging floods as a framework for assessment. Flood Hazards and Disasters, D. J. Parker, Ed., Routledge, in press.

- , and C. W. Landsea, 1998: Normalized hurricane damages in the United States: 1925-95. Wea. Forecasting, 13, 621-631.

—, and M. W. Downton, 1999: U.S. trends in streamflow and precipitation: Using societal impact data to resolve an apparent paradox. Bull. Amer. Meteor. Soc., 80, 1435-1436.

Rayner, S., and E. L. Malone, Eds., 1998: Human Choice and Climate Change. Vol. 1. Batelle Press, 490 pp.

—, and —_. Eds., 1998: Human Choice and Climate Change. Vol. 2. Batelle Press, $451 \mathrm{pp}$.

- and - Eds., 1998: Human Choice and Climate Change. Vol. 3. Batelle Press, 429 pp.

- and - Eds., 1998: Human Choice and Climate Change. Vol. 4. Batelle Press, 193 pp.

Renshaw, E. F., 1957: Toward Responsible Government: An Economic Appraisal of Federal Investment in Water Resources Programs. Idyia Press, 164 pp.

Smith, D. I., 1993: Greenhouse climatic change and flood damages, the implications. Climatic Change, 25, 319-333.

Stevens, W. K., 1997: Experts on climate change ponder: How urgent is it? New York Times, 9 September, p. C1.

Trenberth, K. E., 1997: Global warming: It's happening. NaturalSCIENCE, I. [Available online from www.naturalscience.com/ ns/articles/01-09/ns_ket.html.]

—_ 1998: Atmospheric moisture residence times and cycling: Implications for rainfall rates and climate change. Climatic Change, 39, 667-694.

_ 1999: Conceptual framework for changes of extremes of the hydrologic cycle with climate change. Climatic Change, 42, 327-339.

University of Colorado Natural Hazards Center, 1992: Floodplain Management in the United States: An Assessment Report. Vol. 2, Full Report, Federal Emergency Management Agency, 609 pp.

Ward, R. C., and M. Robinson, 1990: Principles of Hydrology. Whitstable Litho Ltd., 365 pp.

Wiener, J. D., 1996: Research opportunities in search of federal flood policy. Policy Sci., 29, 321-344.

White, G. F., W. C. Calef, J. W. Hudson, H. M. Mayer, J. R. Sheaffer, and D. J. Volk, 1958: Changes in Urban Occupance of Flood Plains in the United States. University of Chicago Press, 235 pp.

Witt, J. L., 1998: National Press Club Luncheon Speech, 10 November 1998. [Available online at www.fema.gov/library/ wittspch11.htm.]

Yen, C., and B. Yen, 1996: A study on the effectiveness of flood mitigation measures. Proc. First Int. Conf. on New/Emerging Concepts for Rivers, Rivertech 96. Vol. 2, Urbana, IL, International Water Resources Association, 555-562. 